\title{
Taking a non-confrontational
}

\section{approach}

Dr Lynn Stephens, dento-legal adviser with BDA Indemnity, takes a

philosophical view of the different views expressed by patients and settles for a non-confrontational approach whilst COVID-19 is still a concern

\section{A point of view}

During my twenty-odd year career in general dental practice there were occasional days, often a Friday for some reason, when I went home after work wondering 'is it me?' Almost all the patients whom I had seen that day appeared to me, to be unusual, somewhat strange, or even completely off the wall. How was it that the receptionist managed to book them all in on the same day? Was she trying to tell me something? I started to wonder if the opposite was true; they were all 'normal' and I was the exception?

The pandemic seems, to an extent, to have polarised the patient behaviour that dental colleagues are having to deal with. Our dentolegal inbox is full of requests for assistance in dealing with complaints from patients who have been requested to wear a mask, been asked to wait in their car, have been sitting in a cold surgery with the windows open, or whose treatment had to be rearranged because an aerosol generating procedure was required.

\section{Seemingly odd}

Two years ago, we could never have dreamed that we would be asking patients to adopt such odd behaviour. This may be the current normal dictated by the prevailing SOP, but perhaps it is possible to understand that patients consider the procedure to be very strange and can become frustrated and annoyed, particularly when they are also exposed to a variety of other mixed and contradictory messaging associated with COVID-19.

The dental team is currently under immense pressure to comply with current guidance, whilst chasing targets, and trying to keep their business afloat. The last thing that is needed is a slightly disgruntled patient or, worse still, an argumentative, aggressive, or abusive patient upsetting the staff and generally causing disruption,

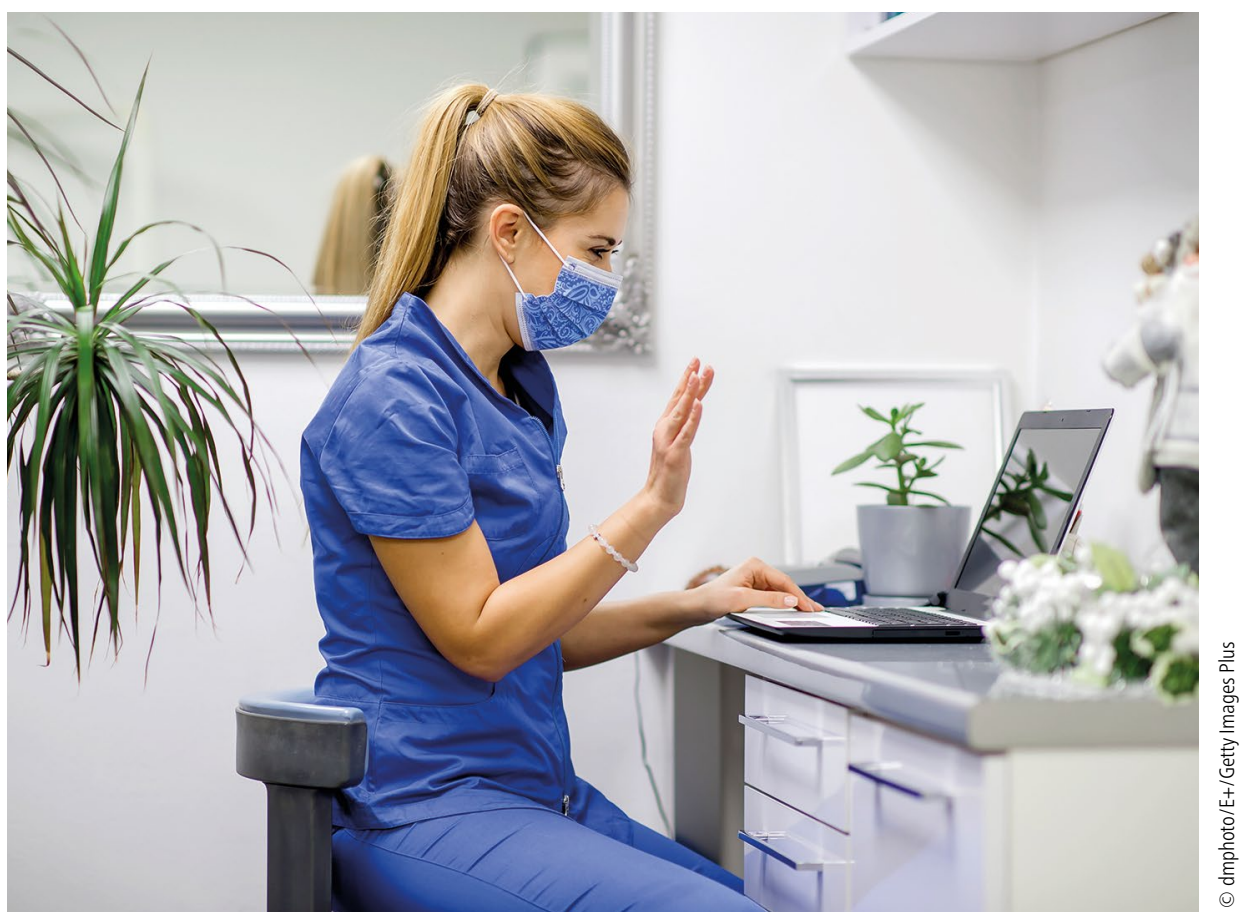

especially if their views are firmly held but not mainstream. Unfortunately, there seem to be plenty around.

\section{Dial down emotions}

Although it is upsetting to receive any sort of complaint try not to take it personally you are not alone and have many colleagues in a similar situation. Keep trying to communicate sympathetically even if many patients seem unprepared to listen.

Of course, there are patients with views which don't quite reflect the current scientific advice about COVID-19. As a clinician, I find it very difficult to understand how anyone could ignore public health advice, particularly when it is supported by a vast mountain of international data. We need to be tolerant of the opinions of others until they are similarly persuaded.

\section{Constant in their variety}

Looking back, I think one or two of my patients may have had underlying mental health issues, but the vast majority were simply demonstrating the very wide range of foibles and eccentricities that we all probably have to some degree. I recollect several occasions when in-surgery conversations were lengthy and sometimes rather bizarre, but a willingness to listen and to try to communicate empathetically seemed to prevent any real dissatisfaction. The fact that many of these patients all attended on the same day was probably simply due to our recall system and not a coded message from the receptionist.

https://doi.org/10.1038/s41404-021-0995-x 